This item was submitted to Loughborough's Research Repository by the author.

Items in Figshare are protected by copyright, with all rights reserved, unless otherwise indicated.

\title{
Gender on the flightdeck: experiences of women commercial airline pilots in the UK
}

PLEASE CITE THE PUBLISHED VERSION

http://dx.doi.org/10.1016/j.jairtraman.2015.04.001

PUBLISHER

(C) Elsevier Ltd

VERSION

AM (Accepted Manuscript)

\section{PUBLISHER STATEMENT}

This work is made available according to the conditions of the Creative Commons Attribution-NonCommercialNoDerivatives 4.0 International (CC BY-NC-ND 4.0) licence. Full details of this licence are available at: https://creativecommons.org/licenses/by-nc-nd/4.0/

\section{LICENCE}

CC BY-NC-ND 4.0

\section{REPOSITORY RECORD}

McCarthy, Faye, Lucy C.S. Budd, and Stephen G. Ison. 2019. "Gender on the Flightdeck: Experiences of Women Commercial Airline Pilots in the UK". figshare. https://hdl.handle.net/2134/17444. 


\title{
Gender on the flightdeck: Experiences of women commercial airline pilots in the UK
}

\author{
Faye McCarthy, Lucy Budd, Stephen Ison
}

Transport Studies Group, School of Civil and Building Engineering, Loughborough University

Accepted for publication in JATM (2015)

Keywords: Pilots, flightcrew, gender, UK

\begin{abstract}
The reasons for, and the implications arising from, the underrepresentation of women on the flightdeck of commercial aircraft continues to challenge national Governments, the aviation industry, and the academic community. Although some airlines have made concerted efforts to improve the gender balance of their flightcrew, womens' participation in the profession remains low. Of the 130,000 airline pilots worldwide only 4,000 (3\%) are women and only 450 hold the command of Captain. The dominant historical discourse of airline pilots as assertive masculine figures may act to dissuade women from pursuing a career on the flightdeck and women pilots are subjected to sexist remarks and behaviour from colleagues and passengers. Given commercial aviation's increasing growth worldwide and the concurrent increase in demand for highly skilled labour, the inability to recruit and retain women pilots represents a significant problem for both the sector and the wider economy as it will constrain growth, hinder aviation's expansion by failing to capitalise on women's skill sets, and delay the achievement of gender equality. Understanding the experiences of flightcrew is therefore vital in addressing this important research problem. Through the use of in-depth interviews with men and women flightcrew in the UK, the research identifies a number of obstacles to greater female participation and recommends that airlines not only focus on gender differences in learning, leadership and communication but that they also take steps to more effectively manage diversity in their workforce and actively promote positive representations of women flightcrew both within and beyond their organisation.
\end{abstract}

\section{Highlights}

- Women are underrepresented on the flightdeck of commercial aircraft.

- In-depth interviews are used to examine the experiences of women pilots in the UK

- Women experience barriers to entry and sexist attitudes in the workplace

- Lack of women mentors is an issue but women find the career rewarding

- Recommendations are proposed that may help airlines address the gender imbalance. 


\section{Introduction}

Although women have been flying since the beginning of the twentieth century (Corn 1979; Stepanski 2012) and flying commercially for over four decades, they continue to be underrepresented on the flightdeck of commercial aircraft (Saner 2014). Of the 130,000 airline pilots worldwide only 4,000 (3\%) are women and of the 3,000 who hold the command of Captain, only 450 are women (Pawlowski 2013; WIA 2012). There are likely to be many reasons that contribute to this imbalance including public perceptions of what constitutes typically 'female' or 'male' professions and the perceived or actual (in)flexibility of the job.

Recent research by British Airways (2013) on the career aspirations of 650 school children aged 6 to 12, for example, discovered that while becoming a pilot was the second most popular career aspiration for boys it was not considered by girls who opted instead for more traditional 'female' careers in healthcare, popular culture and education. As Ashcraft (2007) has shown, the conscious historical construction of commercial and military pilots in popular and institutional discourses as skilful, brave, professional and, above all, masculine, has resulted in a profound gender imbalance among flightcrew as many women do not consider a career in the flightdeck. Those that do enter the profession and qualify as pilots often encounter sexist attitudes, remarks and behaviour from their (overwhelmingly male) instructors, peers and eventual colleagues (Davey and Davison 2000; Mitchell et al 2006).

Nor are such opinions confined to the flightdeck. In a passenger survey conducted in 2012, $51 \%$ of respondents reported that they were less likely to trust a woman pilot and 32\% believed men would be 'more skilled' as pilots than women (Anderson 2014) despite research showing no significant difference in accident rates between men and women (McFadden 1996; Bazargan and Guzhva 2011). Given pervasive historical, cultural and popular perceptions of piloting as 'male' work and the evident gender imbalance in the flightcrew population this paper reports on the findings of a series of in-depth interviews with airline pilots of both genders in the UK. It identifies some of the barriers which may prevent women from entering the profession, examines current experiences of women flightcrew (and their men colleagues' perceptions of them), and makes recommendations as to how best to support flightcrew of both genders to ensure airlines continue to attract and retain highly talented employees and effectively manage diversity in the workplace.

\section{Literature Review}

Despite women performing a number of highly visible roles in the airline industry, most notably as cabin crew and check in staff, the proportion of qualified women aerospace engineers, air traffic controllers and pilots remains low. According to UK Civil Aviation Authority (CAA) figures (CAA 2013), 450 women held an ATPL (Airline Transport Pilot Licence) in the UK in 2013 compared to 10,478 men. At British Airways (BA), the country's largest full service carrier, the proportion is slightly higher. 5.7\% of BA pilots are women and, like many other airlines, the company is keen to encourage applications from suitably qualified women (BA 2013). However, as numerous studies have shown, historical gender biases in degree subjects studied at university combined with biased recruitment policies, inflexible employment terms and negative perceptions of women in traditionally 'male' professions including areas of medicine, engineering, law and academia have resulted in a gender hierarchy within these professions in which women are underrepresented at almost all levels, most notably in the more senior positions (Germain et al 2012; Turney and Maxtant 2004; Katila and Merilainen 1999). 
There is a scarcity of literature on the career decisions of women pilots. Possible factors influencing a woman's decision to become a pilot include funding the training, personality traits that they believe to be unsuitable and lack of women role models (Chusmir 1983; Holland, 1996; Mitchell et al 2006). Women who seek to enter traditionally male dominated careers face the challenge of confronting gender, educational and occupational stereotypes concerning their physical, cognitive and psychological abilities and suitability to undertake such roles (Simeone 1986). As a consequence, Sitler (2004) suggested that the perceived difficulties associated with entering a 'macho' industry dominated by men prevent some women from believing they could become flightcrew. Gibbon (2014) agrees, concurring that flying is often viewed of as a 'boys club.' A study of women airline pilots in the US found that $80 \%$ of respondents said that it was difficult to enter the profession owing to male resistance and being obliged to work with men who resented them entering 'their' profession (Hynes and Puckett 2011). As Deborah Douglas (2004 p256) pertinently noted in her study of American women aviators, although 'the airplane may not be able to distinguish the sex of a pilot (or engineer, air traffic controller, flight attendant, or assembler)... human beings can and do' and it is this issue which has arguably contributed to the current gender imbalance in the flightdeck population.

Women pilots often find themselves discriminated against on grounds of their gender (Sitler 2004). When applying for jobs, Neal-Smith (2014) found some women experiences discrimination, similarly Mitchell et al's (2006) study in Australia discovered that while trainee women pilots scored significantly higher than men on performance measures during initial training, both men and women recruits held negative perceptions of women pilots' proficiency. These negative perceptions were also evident in a South African study (Vermeulen and Mitchell 2007) which found significant differences between men and women's flight instructors' perceptions of women's flying ability. Such findings aligned with previous studies which found that women pilots had to work harder to prove themselves and that they often felt severely pressured to maintain a consistently (and perhaps unrealistically) high level of performance (Davey and Davison 2000; Sitler 2004).

Davey and Davidson (2000) compared the experiences of women pilots who began working for a European airline over a decade ago with the experiences of women pilots recruited to the same airline more recently. The study found that the first women to fly for the carrier believed the men pilots found it difficult to adapt to women on the flightdeck as they found it difficult to communicate effectively or instigate appropriate topics of conversation. The women pilots also claimed that some men colleagues were aggressive and intimidating while some acted in ways that would constitute sexual harassment. Significantly, the women pilots who had joined the airline more recently reported far fewer occurrences of such behaviour and thought that cultural shifts in the perception of women pilots and women in the workplace more generally were partly responsible for this. Despite the improvements, Davey (2004) found that many women felt unsupported and isolated.

The nature of the profession demands that pilots (particularly long haul crew) spend time away from home and, in the past, overseas trips have involved male flightcrew behaving in ways that they would not at home (Davey and Davison 2000). On such trips, drinking, socialising and 'pilot talk' were commonplace. These traits became synonymous with a notion of what constituted a 'typical pilot' who was, of course, a man (Ashcraft 2005). In order to fit in to this masculine environment and be accepted, some women pilots found that they had to be accepting of sexist remarks, be able to brush off lewd jokes and be willing to laugh at demeaning stereotypes (Davey and Davison 2000). Ways in which women in male- 
dominated industries cope with their gender have been explored, Maddock (1999) identifies women manage their gender and try not to change the masculine culture. Women adapt their behaviours to actively fit the environment (Neal-Smith 2014). The type of woman to overcome the barriers pursuing a pilot career must show dedication and drive to succeed (Mitchell et al 2005) whilst tending to adopt a career focused lifestyle due to the difficulty in managing both a career and a family (Bagilhole 2002). Women also face a further, unique set of issues concerning pregnancy, maternity leave, and flexible phased returns to work which not only fit around childcare and domestic commitments but enable sufficient flying hours to be retained for them to remain qualified. It is common in industries that women either become women or mothers (Colgan and Tomlinson 1996) however Neal-Smith (2014) quotes one woman pilot arguing that airlines are more likely to lose young men pilots to another airline than they are women to motherhood.

Given these diverse complex challenges and the continuing underrepresentation of women on the flightdeck, it is imperative that academics and airlines fully understand the reasons why more women don't pursue a pilot career. There is also an urgent need for empirically informed academic research which will enable airlines to adopt measures that better support the recruitment, retention, and positive employment experiences of all pilots, irrespective of their gender.

\section{Method}

In order to further academic insight into this compelling research issue, 10 in-depth semistructured face-to-face interviews were conducted with commercial flightcrew based in the UK. The respondents ( 6 men and 4 women) were recruited through a snowball sample and face-to-face interviews were conducted during the winter of 2013/14. This approach yields rich empirical qualitative data and allows respondents to discuss feelings and emotions (Bryman 2012). Individual interviews also allow for a controlled response and the face to face element means body language can be judged (Moore 2000:118). The snowball sampling technique enabled the respondents within the target population to introduce the research to others (Oppenheim 2005; Walliman 2006). Contact with a few members of the target sample was made via email and these individuals were asked to provide contact details of other members in the target sample to increase the number of participants. In order to preserve anonymity, male respondents are identified by the letters A to F and 1 to 4 (for the women pilots) in subsequent sections of this paper (see Table 1).

The semi-structured interview schedule, which was piloted with two flightcrew to ensure the appropriateness of the questions, contained over 20 questions (Table 2). It began by asking for each respondent's age, current rank, flying experience and the type of aircraft they fly. This was followed by four questions relating to their experiences of entering the profession and experiences of initial training. Questions concerning barriers they have encountered since qualifying as a commercial pilot followed. The men pilots were then asked about their experiences of flying with women colleagues and the women colleagues for their experiences of flying with men pilots. Each interview lasted between 30-60 minutes and ethical approval for the work was granted by our institution's ethics committee. The interviews were recorded and transcribed by the lead author and coded according to their manifest content. 
TABLE 1: List of respondents

\begin{tabular}{lllll}
\hline Respondent & Sex & Rank & $\begin{array}{l}\text { Time flying } \\
\text { commercial } \\
\text { aircraft (years) }\end{array}$ & $\begin{array}{l}\text { Hours of } \\
\text { experience on } \\
\text { current aircraft }\end{array}$ \\
\hline A & M & Captain & 25 & 7,000 \\
B & M & Line Captain & 25 & 7,000 \\
C & M & Captain & 24 & 5,000 \\
D & M & Captain & 25 & 6,000 \\
E & M & First Officer & 10 & 3,000 \\
F & M & Captain & 24 & 7,000 \\
& & & \\
1 & F & First Officer & 2 & 500 \\
2 & F & First Officer & 2 & 700 \\
3 & F & First Officer & 1.9 & 500 \\
4 & F & First Officer & 2.5 & 600 \\
\hline
\end{tabular}

TABLE 2: Interview schedule

\begin{tabular}{|c|c|}
\hline Que & \\
\hline 1 & What is your rank/job title? \\
\hline 2 & How long have you been flying for your current employer? \\
\hline 3 & $\begin{array}{l}\text { What aircraft are you currently flying and how many hours experience do you have } \\
\text { on that aircraft? }\end{array}$ \\
\hline 4 & How long have you been flying commercial aircraft for? \\
\hline 5 & Do you consider a pilot as a men dominated field? If so, why is this? \\
\hline 6 & Why do you believe so few women consider being a pilot as a career? \\
\hline 7 & Do you find it hard to balance your career with your family? \\
\hline 8 & Were there differences in the way in which men and women approached training? \\
\hline 9 & Have you flown with a woman co-pilot before? \\
\hline 10 & If yes, have you flown with a woman pilot who is of higher rank to you? Is this rare?* \\
\hline 11 & Do you enjoy flying with women pilots? \\
\hline 12 & How does the atmosphere differ to flying with men? \\
\hline 13 & Do you think women have to work harder within the industry to be accepted? \\
\hline 14 & Do the expectations of women pilots differ to those of men pilots?* \\
\hline 15 & Do you believe women have to prove themselves and their skill set to be accepted? \\
\hline 16 & $\begin{array}{l}\text { Studies have found women pilots tend to adopt masculine type behaviours to conform } \\
\text { to the workplace culture, do you agree? If yes, what types of behaviours are these? }\end{array}$ \\
\hline 17 & $\begin{array}{l}\text { Have you ever encountered a woman flight crew member make a gender related } \\
\text { remark towards you? If yes, please explain* }\end{array}$ \\
\hline 18 & $\begin{array}{l}\text { Have you ever experienced any passengers making gender related remarks, positive } \\
\text { or negative? If yes, please explain. }\end{array}$ \\
\hline 19 & $\begin{array}{l}\text { Have you ever experienced a male colleague make a gender related “jokes” If yes, } \\
\text { please explain? }\end{array}$ \\
\hline 20 & Do you believe gender prejudice by men pilots exists today? Please explain. \\
\hline 21 & $\begin{array}{l}\text { Can you make any recommendations on methods to ensure more women enter the } \\
\text { industry as pilots? }\end{array}$ \\
\hline 22 & Is there anything else you would like to add? \\
\hline
\end{tabular}




\begin{tabular}{l}
\hline Additional Questions asked of women respondents: \\
\hline When entering the industry as a pilot, did you experience any barriers? \\
\hline Do you believe women have to prove themselves and their skill set to be accepted? \\
\hline $\begin{array}{l}\text { Have you ever experienced any cabin crew make gender related remarks, positive or } \\
\text { negative? If yes, please explain. }\end{array}$ \\
\hline Are women cabin crew generally accepting of women pilots? If no, why? \\
\hline
\end{tabular}

\section{Findings}

The 6 male interviewees had an average age of over 50 and included one Line Captain, 4 Captains and 1 First Officer. All flew narrow-bodied, twin engine jets, had been flying commercially between 2 and 25 years and had experience ranging from 400 to 7,000 hours on type. The four women respondents were all First Officers in their early 30s. They also flew narrow-bodied, twin engine jets and have been flying commercially between 21 months and 6 years. Their experience ranged from 500 to 500 hours on type.

\section{Men's Responses}

All the men respondents agreed that piloting is male dominated. Respondent B stated that "statistically, there are more men flying" and opined that the reasons for this are the military background of aviation and because young boys are often more exposed to flying than girls. When asked why so few women might consider a career as a pilot all six men respondents mentioned the role of women within the home and suggested that the pilot lifestyle does not readily lend itself to raising a family. Interestingly, two respondents suggested that the lack of women pilots and mentors means it might be harder for women to progress.

All the men respondents said that they find it difficult to balance their career with their family and made reference to a strong support network at home that enables them to fly abroad and work anti-social hours. Respondent A remarked that "my roster dominates my lifestyle" and "it is very hard with irregular times". Being away from home for extended and/or irregular periods of time was challenging. Four of the six stated they have to "compromise" their career and their family and articulated frustration at often feeling they were doing neither very effectively. Reflecting on their time in initial training, three of the men respondents reported a difference in the ways in which men and women recruits approached new tasks. Respondent E suggested that "I think women were possibly even harder working than men" while respondent B remembered "maybe some of the physical aspects were more demanding and required more strength" which some of the women, owing to their physiology, found more difficult.

In terms of their current experiences of flying, all of the men respondents have experience of flying with a woman pilot but only two have flown with a woman of a higher rank. All stated that they enjoy the experience. According to respondent $\mathrm{D}$ it is "a different type of flight, I enjoy it!" while respondent B stated that "it is becoming more pleasant in the industry and it is nice to have different conversations [with female pilots]". Three respondents stated that the atmosphere on the flightdeck is more relaxed and less competitive when flying with women. “There isn't any of the 'mine is bigger than yours' type of atmosphere" and there "is no issue of gender competitiveness" (Respondents B and E). All six mentioned that the conversations they had with women colleagues were "different" or "more interesting". However, they were also quick to state that while the in-flight conversation topics might differ the "job does not alter" and "the flying is the same" (Respondent C). When asked about the extent to which they believed women pilots might adopt a different behaviour or persona on the flight deck, 
two of the respondents suggested that women may try to appear "harder" and "sterner" in order to be taken seriously as well as occasionally adopting a more "macho" approach.

Five of the men respondents believed women pilots have to work harder within the industry to be accepted and they might feel more pressure in this regard; "it is very sad, but they do, they are perceived differently and they feel like they have to prove themselves" (Respondent A) and "yes-without a doubt!" (Respondent F) but "females are equally as good" (Respondent E). Respondent F went as far as to suggest that "females are more thorough at times", opining that this might be because they want "to prove they are as good as males". Respondent C stated that "they believe they have to work harder to be accepted" and "it is very sad", however Respondent F argued that "males maybe have to prove themselves even more than females" owing to the masculine discourse of piloting.

Five of the six men respondents had experienced a man colleague making a derogatory gender-related remark to a woman pilot but all were quick to emphasise that these comments were "jokes", or "only have been a bit of light hearted banter" which was not to be taken seriously (Respondents $C$ and D). One respondent suggested that older pilots, who are closer to retirement, were more likely to "make stupid comments, such as: women should not be pilots as they belong in the kitchen" than younger ones but these attitudes were declining. Respondent E stated that "in the UK we have brilliant laws and regulations in place to reduce this as much as possible” and they felt such comments would become increasingly rare as the older generation of (often ex-military) pilots retired. Respondent C, however, suggested that sometimes derogatory comments could be used as a way to diffuse tension on the flightdeck "it is sometimes joked when a woman pilot makes a stupid mistake that she should be at home looking after the kids or washing up".

In addition to sexist comments made by colleagues, three respondents had experienced passengers making negative remarks about women pilots. These comments, while unwelcome and unwarranted in their view, were usually made by "old fashioned types of passengers who usually feel blokes are better as pilots and girls as stewardesses" (Respondent C).

In order to promote women in aviation, the overriding view was that current women pilots should attend career events to publicise women in the role as well as "reducing the cost of training and improving the pay and conditions” of all employees (Respondent A). In addition, there was a consensus that more women should enter the profession and gender misconceptions be more effectively challenged at school and university so "women should not feel as though they cannot perform the male tasks” (Respondent A).

\section{Women's Responses}

All four of the women respondents considered piloting to be a male-dominated field. Their rationale for this varied from the "historical divide" of the profession to the "stress and challenging nature of the work" (Respondent 1 ). Respondent 3 explained, "the work can be stressful and challenging and comes with a level of competitiveness that makes it appear masculine”. When entering the profession, none of the women encountered barriers relating to their gender; the obstacles were purely financial "as companies expected you to fund your own type rating” (Respondent 2).

All four respondents believed the lack of women on the flightdeck was an inevitable, if regrettable consequence of young women not being introduced to the possibility of the career 
at school. Respondent 2 identified a lack of exposure to the profession "rather than not thinking it was possible because I am female" while respondent 1 suggested "it isn't pressed at school from an early age". Respondent 3 reflected on the stereotypes and misconceptions of the job which conspired to "make it appeal more to males".

Reflecting on their training, three respondents agreed that their men colleagues were more confident and determined to prove themselves. One suggested that women took criticism from their trainers to heart more than the men which is why they strove to be successful at everything all of the time and placed very high expectations on themselves. Respondent 2 also believed that "all the women worked extremely hard to try and achieve the very best". Interestingly, they did not consider that they had had to work harder than men to prove themselves, and stated that any pressure they felt was self-imposed in a desire to succeed. Respondent 2 said that "a lot of people, for example trainers, often remark that women are better pilots in some cases as they are more attentive, organised, better communicators and good multi-taskers”.

Owing to their age none of the women had started families but they all agreed that the situation with regards to future motherhood "could get tricky" and "may be an issue in the future" (Respondents 2 and 3). However, Respondent 1 was more optimistic, believing the job "can be flexible, so it [pregnancy and parenting] can be worked around."

All four women respondents had flown with another woman pilot but said that this was a rare occurrence owing to the relatively low numbers of women pilots. All enjoyed flying with other women and stated that the atmosphere on the flight becomes more 'feminine' and the conversation topics differ despite their strict adherence to standard operating procedures. Two respondents believed that the job does not require them to adopt masculine type behaviours and flying is "the same whatever the gender of the pilot" (Respondent 2). However, Respondent 3 stated that in adding to being "thick skinned" women pilots "need to be assertive and not be afraid to speak out against more dominant personalities".

Two respondents had not experienced, or could not remember, a man colleague making a gender related remark towards them while the other two dismissed the remarks they had received as "jokes". Respondent 3 recalled situations in which men pilots adapt their behaviour out of consideration for their women colleagues "if the weathers bad, they [the men pilots] will often offer to do the walk around so as not to ruin our hair". All four women respondents agreed that gender stereotypes and prejudice still exist within the flightdeck, but suggested this was a historical legacy, the influence of which was rapidly declining over time.

While the situation with colleagues appears to be improving, all four women had experienced gender-related remarks being made by passengers. Some of these were positive with women passengers, in particular (but not exclusively), often congratulating them on their achievement and asking if they could take their photograph to show to their daughters. However, the majority of comments were perceived negatively with gender-related "jokes" such as “can you park this?” or "are you qualified to fly this?” reportedly being common. Interestingly, both the men and women cabin crew they have flown with were very accepting of women pilots with respondent 4 stating that women cabin crew, in particular, "like the fact a female is in the flight deck".

Recommendations for encouraging more women to enter the profession included having airlines support women pilots in encouraging them to attend schools and events to reach out 
to girls at a young age as well as having access to a more experienced woman mentor to support their career progression. None offered any opinions on pregnancy, maternity leave or supporting women pilots returning to work as this was not something that they had direct experience of. Interestingly, and by way of a final comment, respondent 3 suggested that being a woman in a field dominated by men could actually work in your favour as "a CV [from a women] can stand out because it is a bit different”.

\section{Discussion}

Both men and women pilots indicated that cost and the masculine nature of the profession might put off some women from pursuing a career as a pilot, this is supported by Hamilton (2014) stating the lack of money for flight training being the main barrier for women.

Additionally, the women pilots stated that a lack of awareness of the role of women in aviation at school could be instrumental in limiting the numbers of women who aspired to it as a career. In concordance with this, Gottfredson (2002) identified that exposure to the role is necessary to trigger an interest by women. In order to overcome this, both the men and women respondents advocate a far greater emphasis being placed on raising awareness of the opportunities flying affords and on school and university students being given access to relevant and appropriate careers advice. Several respondents suggested that this could take the form of women pilots going into schools and colleges to promote the role of women flightcrew and act as mentors for women students considering a career in the industry.

During initial training, it was suggested that male recruits may deal with criticism more easily than women. It was felt that some women take criticism to heart and dwell more on their mistakes and shortcomings than their competencies and success which may impact on their confidence and lead to a vicious cycle of self-criticism. In order to counter this, instructors need to be aware of gender differences in learning and be able to adapt their approach to best suit the needs of the individual in recognition that a 'one size fits all' approach to training is not necessarily the most effective way to support a diverse intake of new pilots.

Once in the profession, both genders agree that balancing family life with a pilot career is extremely difficult due to the nature of the work and shift patterns. Interestingly, the men believe that they are more suited to the pilot lifestyle due to women having children and conventionally taking on responsibility for the majority of domestic duties. Lepore (2011) expressed womens' concerns of piloting not being a 'family-friendly' job, however the women pilots strongly disagreed that the career is more suited to men. Throughout their careers, a substantial issue for the women pilots is the need to continually prove their competencies and avoid mistakes (which may be casually and unhelpfully attributed to their gender) to be considered a good pilot. Although the women interviewed for this study enjoy the male dominated environment, we (and they) are aware this may not be true for all women.

In terms of the perceptions of women pilots, two key issues emerged: the perceptions of women pilots by their men peers and the perceptions of women pilots by passengers. KohnStuart (2000) found instructors perceived and expected women to have less technical skill than men, half of the men pilots had experienced a man colleague using derogatory language towards a woman pilot but they were all keen to emphasise that these were just 'jokes'. This suggests men may find the use of derogatory and discriminatory behaviour acceptable, assuming the women will recognise what they perceive to be the 'light-hearted' nature of the 'banter'. These accounts are similar to those found in Davey and Davison (2000), 
highlighting that these experiences are still existent fourteen years later and the attitudes, which were seemingly leaving the profession, have not done so.

The research also indicates the extent of passengers' attitudes towards women pilots. Both the men and women respondents agreed that passengers care about the gender of their pilot and many have experienced remarks being made by passengers when they realise one (or sometimes both) of their flightcrew is a women. While some passengers clearly like to see women flightcrew, these positive comments are few and far between and passengers are often surprised when a woman's voice addresses them from the flightdeck. Negative passenger remarks include a women's apparent inability to park, take control and multitask.

Significantly, these preconceptions do not exist for men pilots and none of the interviewees reported passengers making disparaging remarks about male flightcrew.

It would appear from the interviewees that both genders believe women bring different qualities to the flightdeck as they think and act differently to men. Neal-Smith (2014) identified women adapt their behaviours to the masculine environment, similarly both the men and women respondents noted that pilot gender alters the atmosphere on the flightdeck. Several of the men stated that they prefer flying with women as the environment is more "relaxed". According to men pilots, women may have to adapt their behaviours to fit in, in particular their socialising behaviours which need to be more male-typical and women have to be thick-skinned to take a joke. Nevertheless, it is significant that men do not have to adapt their behaviours, whereas, women pilots recognised that they sometimes have to adopt a sterner attitude to be taken seriously. Despite this, both genders agree that the job does not alter; therefore, it is the individual flying the aircraft, not their gender that matters.

\section{Conclusions}

It is evident that women pilots still believe they have to overcome certain barriers and preconceptions in order to be accepted in what remains an overwhelmingly male profession. Although finance is an issue for both pilots, aspiring women pilots have the added issue of trying to become accepted by their men peers. Additionally, women may place themselves under greater pressure to succeed in the (perhaps misguided) belief that they have to continually prove their worth and 'right' to be there and may dwell on criticism they receive from their instructors.

Once qualified, pilots of both genders face compromises between their home and their career as crew rosters, long haul trips, anti-social hours and nights away from home disrupt normal domestic arrangements and require a good support network to maintain 'normal' family life when one or other partner or parent is absent. Interestingly, the men pilots felt that flying was more suited to men because they did not bear children or bare responsibility for the majority of childcare. The women respondents to this survey, while not having direct personal experience of combining a career as a pilot with motherhood, nevertheless recognised that this might be an issue in the future and further research is needed to ascertain what might constitute the most effective and appropriate mechanisms to support new mothers through pregnancy and parenthood.

At a broader societal level, there is a need to challenge the dominant cultural discourse that continues to portray piloting as 'men's work'. Although this will take considerable time and concerted effort, it is hoped that reframing the profession as one that is equally suited to, and welcoming of, both men and women pilots will filter down to school age children and not only create a more equal balance of $\mathrm{m}$ and women pilots but also work to promote gender 
equality more broadly and reduce the temptation (and societal acceptance) of the casually sexist remarks from colleagues and passengers that women pilots currently encounter.

While it will not be possible to change some of the entrenched negative perceptions and attitudes certain individuals hold towards women pilots, as more women enter the profession, passenger expectations of hearing a man's voice from the flightdeck will be reduced and women pilots will become an increasingly familiar and unremarkable sight. As the older generation of men pilots retire and are replaced by younger colleagues, many of the outdated attitudes will hopefully be replaced by a more open and inclusive set of opinions towards the place of both men and women in the workforce.

Although gender-related attitudes and experiences within the career are still evident, notable improvements have been brought about through the implementation of gender equality policies and regulations. However, while progress has undoubtedly been made, there is room for continual improvement. Schools, colleges, universities, flight training academies, airlines and society more generally must collectively seek to promote the role of women in aviation. By ensuring that more young women are exposed to the profession and are given appropriate education advice about school subjects and relevant university degree programmes that will enable them to become a pilot if they so wish, as well as adopting mentoring programmes for women recruits and introducing family and women friendly recruitment, retention and career progression and promotion policies will only be to the industry's long term benefit. Further research needs to identify a theoretical underpinning to women's decisions to entering the pilot profession.

\section{Acknowledgements}

The authors would like to thank the interviewees for sharing their time and experiences with us as well as participants at the 2015 Transportation Research Board session on women in transportation and the two referees for their very helpful and constructive comments.

\section{References}

Anderson, S. (2014) Who do you trust more, male or female pilots?

http://www.sunshine.co.uk/news/who-do-you-trust-more,-male-or-female-pilots-105.html. Accessed February 25, 2014.

Ashcraft, K. L. (2005) Resistance through consent? Occupational identity, organizational form and the maintenance of masculinity among commercial airline pilots Management Communication Quarterly 19, pp. 27-90.

Ashcraft, K. L. (2007) Appreciating the 'work' of discourse: occupational identity and difference as organising mechanisms in the case of airline pilots Discourse and Communication 1, pp. 9-36.

Bagilhole, B.M. (2002). Women in Non-traditional Occupations: Challenging Men. New York: Pelgrave, Macmillan.

Bazargan, M. and Guzhva, V. S. (2011) Impact of gender, age and experience of pilots on general aviation accidents. Accident Analysis and Prevention 43, pp. 962-970. 
British Airways. (2013) Disney’s Planes inspires a generation of pilots.

http://www.britishairways.com/en-

gb/bamediacentre/newsarticles?articleID=20140115090828\&articleType=LatestNews\#.UwY d-Pl_vTo). Accessed February 2, 2014.

Brown, J. (2000). Occupational Culture as a factor in the stress experiences of police officers. In F. Leishman, B. Loveday and S. Savage (eds), Core Issues in Policing, $2^{\text {nd }}$ edn. Harlow: Pearson Educational, pp.249-263.

Bryman, A. (2012).Social Research Methods, $4^{\text {th }}$ Edition, Published by Oxford University Press, Inc, New York

Chusmir, L.H. (1983). Characteristics and predictive dimensions of women who make nontraditional vocational choices. Personnel and Guidance Journal, 62(1), pp. 43-47.

Civil Aviation Authority [CAA]. (2013) Response to Freedom of Information Request. Proportion of female pilots.

https://www.whatdotheyknow.com/request/number_of_female_pilots?unfold=1. Accessed March 6, 2014.

Colgan, F. and Tomlinson, F., (1996). Women in book publishing: A 'feminised' sector? In: S. Ledwith and F. Colgan (eds), Women in Organizations: Challenging Gender Politics, London: Macmillan, pp.44-77.

Corn, J. J. (1979) Making flying 'thinkable': Women pilots and the selling of aviation, 19271940 American Quarterly 31(4), pp. 556-571.

Davey, C. and Davidson, M. (2000) The Right of Passage? The Experiences of Female Pilots in Commercial Aviation. Feminism and Psychology 10(2), pp. 195-225.

Davey, C.L. (2004). The Impact of Human Factors on Ab Initio Pilot Training. Gender, Work and Organization, 11(6).

Douglas, D. (2004) American Women and Flight since 1940 University of Kentucky Press, Lexington.

Germain, M. L., Herzog, M. R. and Hamilton, P. R. (2012) Women employed in maledominated industries: lessons learned from female aircraft pilots, pilots-in-training and mixed-gender flight instructors. Human Resource Development International, 15(4), pp. 435453.

Gibbon, D. (2014). Difficult, Dangerous, Not a Job for Girls: Factors Impacting Women and Girls` Orientation Towards Pilot Careers, in Bridges, D., Neal-Smith, J., and Mills, A.J. (eds), Absent Aviators, Gender Issues in Aviation. Chapter 2. Ashgate, UK.

Gottfredson, L. S. (2002). Gottfredson's theory of circumscription, compromise, and self creation. In D. Brown (Ed.), Career choice and development (4th ed., pp. 85-148). San Francisco: Jossey-Bass. 
Hamilton, P. R (2014). The Teaching Women to Fly Research Project. , in Bridges, D., NealSmith, J., and Mills, A.J. (eds), Absent Aviators, Gender Issues in Aviation. Chapter 13. Ashgate, UK.

Holland, J.L. (1996). The Psychology of Vocational Choices: A Theory of Personality Types and Model Environments. Waltham, MA: Blaisdall Publications Company.

Hynes, G. E. and Puckett, M. (2011) Feminine Leadership in Commercial Aviation: Success Stories of Women Pilots and Captains. Journal of Aviation Management and Education, pp.1-6.

Katila, S. and Merilainen, S. A. (1999) Serious Researcher or Just Another Nice Girl? Doing Gender in a Male-Dominated Scientific Community. Gender, Work and Organization 6(3), pp. 163-173

Kohn-Stuart, R. (2000). Gender differenced in the cockpit. In: 2000 Asia-Pacific Women in Aviation Conference, Canberra, Australia.

Lepore, M. (2011). Female pilots are few and far between: Here are some reasons why. Grindstone Blog and Discussion Forum, $7^{\text {th }}$ July. [Online]. $<$

http://www.thegrindstone.com/2011/07/07/mentors/female-pilots-are-few-and-far-betweenhere-are-some-reasons-why/>

Maddock, S., (1999). Challenging Women: Gender, Culture and Organisation. London: Sage. McFadden, K. L. (1996) Comparing pilot-error accident rates of male and female airline pilots Omega 24(4), pp. 443-450.

Mitchell, J., Kristovics, A., Vermeulen, L., Wilson, J. and Martinussen, M., (2005). How pink is the sky? A cross-national study of the gendered occupation of pilot. Employment Relations Record, 5(2).

Mitchell, J., Kristovics, K. and Vermeulen, L. (2006) Gender Issues in Aviation: Pilot Perceptions and Employment Relations International Journal of Employment Studies 14(1), pp.35-39.

Moore, N. (2000). How to do research. The complete guide to designing and managing research projects. Third edition. Library Association Publishing, London.

Neal-Smith, J. (2014). Flying Through Barriers: Identifying Issues for Female Airline Pilots. , in Bridges, D., Neal-Smith, J., and Mills, A.J. (eds), Absent Aviators, Gender Issues in Aviation. Chapter 8. Ashgate, UK.

Oppenheim, A.N. (2005). Questionnaire Design, Interviewing and Attitude Measurement: new edition. Continuum, London.

Pawlowski, A. (2013). Why aren’t more women airline pilots? CNN October 30, 2013. http://edition.cnn.com/2011/TRAVEL/03/18/female.airline.pilots/ Accessed March 1, 2014. 
Saner, E. (2014) Female pilots: a slow take-off. The Guardian January 13, 2014 http://www.theguardian.com/lifeandstyle/2014/jan/13/female-pilots-woman-flying-aeroplane. Accessed March 1, 2014.

Simeone, A. (1986) Academic Women: Working Towards Equality. South Hadley, Massachusetts, J F Bergin and Garvey.

Sitler, R. (2004) Gender differences in learning to fly. In M. A. Turney (Ed.), Tapping diverse talents in aviation: Culture, gender, and diversity Aldershot, Ashgate. pp.77-88.

Stepanski, L. M. (2012) Like Sportive Birds: The Girl Aviator Series and the Culture of Flight in America, 1911-12 The Journal of Popular Culture 45(4), pp.769-788.

Turney, M. A. and Maxtant, R. F. (2004) Tapping diverse talent: A must for the next century. In Turney, M. A. (Ed.) Tapping diverse talent in aviation: Culture, gender, diversity. Aldershot, Ashgate, pp. 3-10.

Vermeulen, L. and Mitchell, J. (2007) Development and validation of a measure to assess perceptions regarding gender-related pilot behaviour. International Journal of Aviation Psychology, 17(2), pp. 197-218.

Walliman, N. (2006). Social Research Methods. Sage Publications Ltd, London.

Women in Aviation [WIA]. (2012) Women in Aviation: The Facts. https://www.wai.org/resources/facts.cfm. Accessed March 1, 2014 